University of Nebraska - Lincoln

DigitalCommons@University of Nebraska - Lincoln

Nebraska Cooperative Fish \& Wildlife Research Nebraska Cooperative Fish \& Wildlife Research Unit -- Staff Publications

1996

\title{
EFFECTS OF RED IMPORTED FIRE ANTS ON NORTHERN BOBWHITE CHICKS
}

William M. Giuliano

Texas Tech University

Craig R. Allen

Texas Tech University, callen3@unl.edu

R. Scott Lutz

Texas Tech University

Stephen Demarais

Texas Tech University, steve.demarais@msstate.edu

Follow this and additional works at: https://digitalcommons.unl.edu/ncfwrustaff

Part of the Other Environmental Sciences Commons

Giuliano, William M.; Allen, Craig R.; Lutz, R. Scott; and Demarais, Stephen, "EFFECTS OF RED IMPORTED FIRE ANTS ON NORTHERN BOBWHITE CHICKS" (1996). Nebraska Cooperative Fish \& Wildlife Research Unit -- Staff Publications. 52.

https://digitalcommons.unl.edu/ncfwrustaff/52

This Article is brought to you for free and open access by the Nebraska Cooperative Fish \& Wildlife Research Unit at DigitalCommons@University of Nebraska - Lincoln. It has been accepted for inclusion in Nebraska Cooperative Fish \& Wildlife Research Unit -- Staff Publications by an authorized administrator of DigitalCommons@University of Nebraska - Lincoln. 


\section{EFFECTS OF RED IMPORTED FIRE ANTS ON NORTHERN BOBWHITE CHICKS}

WILLIAM M. GIULIANO,' Department of Range and Wildlfe Management, Texas Tech University, Lubbock, TX 79409, USA CRAIG R. ALLEN, ${ }^{2}$ Department of Range and Wildlife Management, Texas Tech University, Lubbock, TX 79409, USA R. SCOTT LUTZ, ${ }^{3}$ Department of Range and Wildlife Management, Texas Tech Unlversity, Lubbock, TX 79409, USA STEPHEN DEMARAIS, Department of Range and Wildlife Management, Texas Tech University, Lubbock, TX 79409, USA

Abstract: Populations of red imported fire ants (RIFA; Solenopsis invicta) have spread rapidly throughout the southeastern United States. RIFA, directly or indirectly, negatively affect many wildlife species, and northern bobwhite (Colinus virginianus) appear to be particularly susceptible. We examined the effect of exposure to different numbers of RIFA for 15 and 60 seconds on body mass and survival of captive northern bobwhite chicks. Compared to unexposed birds, survival of chicks was reduced with exposure to as few as 50 RIFA for 60 seconds, or 200 RIFA for 15 seconds, and body mass was lower in chicks exposed to 200 RIFA for 60 seconds. Our results support the hypothesis that quail populations can be adversely affected by direct exposure to RIFA.

J. WILDL. MANAGE, 60(2):309-313

Key words: body mass, chick, Coolinus virginilamus, northem lbobwhite, red imported fire ant, Solenopsis invicta, survival.

Red imported fire ants megatiwely affect numerous invertebrate and vertebrate species, presumably due to predation, and direct and indirect competition (Johnson 1961, Allen et al. 1994, 1995). Effects on vertebrate populations are less well documented than effects on invertebrates (Allen et al. 1994). Among affected vertebrates, northern bobwhite have received the most attention. This attention may be due to their importance as game birds or as a result of the controversy of whether RIFA are detrimen-

\footnotetext{
' Present address: Department of Biological and Environmental Sciences, California University of Pennsylvania, California, PA 15419, USA.

${ }^{2}$ Present address: Department of Wildlife Ecology and Conservation, University of Florida, Gainesville, FL 32611-0430, USA.

${ }^{3}$ Present address: Department of Wildlife Ecology, University of Wisconsin, Madison, WI 53706, USA.
}

tal to northern bobwhite populations (Allen et al. 1993, Brennan 1993). Recent research has shown that RIFA at high densities have a negative effect on northern bobwhite numbers in the Texas coastal bend (Allen et al. 1995). That research did not, however, address the type of effect.

Allen et al. (1995) proposed 3 mechanisms of RIFA effects on quail populations: (1) direct effect (predation) on pipping chicks, (2) indirect effect on food supply (i.e., invertebrates) of $<2$ week-old chicks and hens during reproduction, and (3) negative effect from exposure to fire ant stings. Fire ants may directly affect pipping chicks, causing 6-12\% mortality (Johnson 1961, Dewberry 1962). RIFA effects on invertebrate species abundance and diversity that may indirectly affect northern bobwhite survival and recruitment is well documented (Fillman and 
Table 1. Survlval rates (9-day period) and mean number of red Imported fire ants (RIFA) on northern bobwhite chlcks exposed to different numbers RIFA for 15 or 60 seconds, Texas 1993.

\begin{tabular}{|c|c|c|c|c|c|c|c|c|}
\hline \multirow[b]{3}{*}{ Treatment } & \multirow{3}{*}{$\begin{array}{l}\text { \# RIFA } \\
\text { exposed }\end{array}$} & \multirow{3}{*}{$\begin{array}{l}\text { Duration of } \\
\text { exposure } \\
\text { (sec) }\end{array}$} & \multirow{2}{*}{\multicolumn{2}{|c|}{ \# RIFA on chick }} & \multicolumn{3}{|c|}{ Survival rate } & \multirow[b]{3}{*}{$P^{\mathbf{a}}$} \\
\hline & & & & & \multirow[b]{2}{*}{$x$} & \multicolumn{2}{|c|}{$90 \%$ Confldence limits } & \\
\hline & & & $\boldsymbol{t}$ & SE & & lower & upper & \\
\hline 1 (control) & 0 & 60 & 0 & - & 1.00 & 1.00 & 1.00 & - \\
\hline 2 & 10 & 60 & 2.6 & 0.64 & 0.94 & 0.85 & 1.00 & 0.310 \\
\hline 3 & 25 & 60 & 6.2 & 0.94 & 1.00 & 1.00 & 1.00 & 1.000 \\
\hline 4 & 50 & 60 & 6.5 & 1.43 & 0.89 & 0.77 & 1.00 & 0.096 \\
\hline 5 & 100 & 60 & 16.9 & 1.99 & 0.89 & 0.77 & 1.00 & 0.096 \\
\hline 6 & 200 & 60 & 33.9 & 2.41 & 0.44 & 0.23 & 0.64 & $<0.001$ \\
\hline 7 & 50 & 15 & 5.2 & 0.83 & 1.00 & 1.00 & 1.00 & 1.000 \\
\hline 8 & 100 & 15 & 9.0 & 1.38 & 1.00 & 1.00 & 1.00 & 1.000 \\
\hline 9 & 200 & 15 & 22.5 & 1.72 & 0.88 & 0.75 & 1.00 & 0.089 \\
\hline
\end{tabular}

a Compared to treatment 1 (control) using a likelihood ratio Chi-square statistic $\left(\mathrm{G}^{2}\right)$ following methods described by White (1983).

Sterling 1983, Porter and Savignano 1990). However, effects of northern bobwhite exposure to RIFA stings are unknown.

Northern bobwhite are exposed to varying densities of RIFA infestation throughout much of their range, and there is high potential for northern bobwhite in the wild to be stung by RIFA. Disturbance of worker individuals, foraging columns, or nests results in an immediate stinging response by the ants. Our objective was to test the hypothesis that exposure to RIFA has an effect on northern bobwhite chick survival and body mass. To test this hypothesis, we exposed 4-day-old northern bobwhite chicks to different numbers of RIFA for different amounts of time.

Our work was supported by the San Antonio Livestock Show; the Fire Ant Line Item at Texas Tech University, Department of Plant and Soil Science; and the Noxious Brush and Weed Control Program, Department of Range and Wildlife Management, Texas Tech University. We thank N. Mancha for help with data collection; D. B. Wester for statistical advice; and C. Davis, K. Launchbaugh, and S. Phillips for reviewing earlier drafts of the manuscript. This study was approved by the Texas Tech University Animal Care and Use Committee (ACUC 92264) and is College of Agricultural Sciences and Natural Resources publication T-9-730 and Rob and Bessie Welder Wildlife Foundation publication $\mathbf{4 5 2}$.

\section{METHODS}

One week before experiments, 10 intact RIFA mounds were collected near McFadden, Victoria County, Texas. Mounds were placed in
19-L plastic containers, and transported to the Red Imported Fire Ant Research Lab, Department of Plant and Soil Sciences, Texas Tech University.

We purchased 2-day-old northern bobwhite chicks from a commercial breeder (Stevenson Game Bird Farm, Riverside, Tex.). Chicks were banded upon arrival and placed in a $2-\times 1-\times$ 1 1-m elevated box brooder with a $0.63-\mathrm{cm}$ mesh floor. One heat lamp was placed at each end of the brooder to provide heat for chicks. Temperature beneath the lamps was about $38 \mathrm{C}$ and chicks could individually regulate body temperature by moving away from the lamps. Throughout the study chicks were given water and food (Purina ${ }^{\circledR}$ Gamebird Starter, St. Louis, Mo.) ad libitum.

Chicks were weighed $( \pm 0.01 \mathrm{~g}$; using a Metlar PE 1600 balance) and assigned, using a randomized design, to $l$ of 9 treatment groups (18 chicks/ treatment) $l$ day before the experiment. We varied the number of RIFA and exposure duration of chicks (Table 1 ). We placed individual 4-day-old chicks in each of 9 4-L glass beakers containing either $0,10,25,50,100$, or 200 RIFA for 60 seconds or 50,100 , or 200 RIFA for 15 seconds. We recorded the number of RIFA that climbed onto the chicks. We returned chicks to a heated holding box until all 163 chicks were treated. We then placed all chicks in the brooder for the remainder of the study. RIFA are difficult to handle, and unlikely to sting when induced individually (Hunt and Hermann 1973), therefore, we exposed chicks to different numbers of ants, rather than attempting to quantify number of stings. 
In addition to treated birds, another group of 18 randomly selected chicks remained in the brooder while the other birds were being treated, to compare with the control group (i.e., 0 RIFA for $60 \mathrm{sec}$ ) and determine if our treatment procedure adversely affected the chicks. All chicks were weighed ( $\pm 0.01 \mathrm{~g}$ ) $1,3,5,7$, and 9 days after treatment, and mortalities were recorded daily.

We used an incomplete factorial repeated measures analysis of covariance followed by a Fisher's least significant difference test (SYSTAT 1992) to determine the main effects of exposure to different numbers of RIFA and duration of exposure on body mass of northern bobwhite chicks $1,3,5,7$, and 9 days after treatment. An interaction term (no. of RIFA $\times$ duration of exposure) was not determined because of the incomplete design (SYSTAT 1992). A separate repeated measures analysis of covariance and Fisher's least significant difference test was used to determine differences in body mass between controls and chicks that remained in the brooder during treatment of other birds. In both analyses, pre-treatment body mass was used as a covariate. We calculated survival rates for each treatment group and compared them using a log-linear model following methods described by White (1983). If the log-linear model was significant, pairwise comparisons were made between treatments using a likelihood ratio $\mathrm{Chi}$ square statistic $\left(\mathrm{G}^{2}\right.$; White 1983 , SYSTAT 1992). We used Pearson correlation coefficients $(r)$ to describe the relation between number of RIFA chicks were exposed to in a beaker and mean number of RIFA that climbed onto a chick (SYSTAT 1992).

\section{RESULTS}

We were concerned that our handling procedure would adversely affect chick survival and body mass. However, when we compared control chicks with chicks that did not go through our treatment procedure, we found no effects on survival $(P=1.000)$ or body mass $(P=0.962)$.

\section{Survival}

Chick survival was affected by exposure to different numbers of RIFA $(P<0.001)$. Compared to control birds, survival rates were lower when we exposed chicks to $\geq 50$ RIFA for 60 seconds and 200 RIFA for 15 seconds (Table 1); these exposure rates corresponded to $\geq 6.5$ and

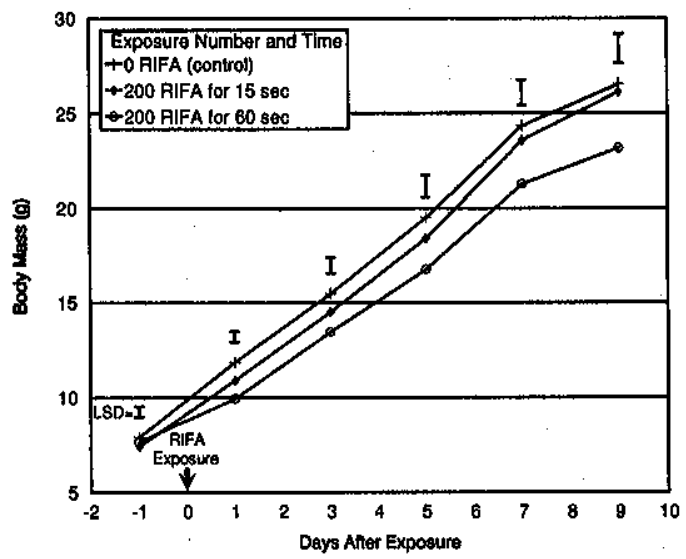

Flg. 1. Body mass of northern bobwhite chicks exposed to red Imported fire ants (RIFA), Texas 1993. LSD = Flsher's least significant difference at $P=0.10$.

$\geq 22.5$ ants on a chick, respectively (Table 1 ). Duration of exposure (15 vs. $60 \mathrm{sec}$ ) to RIFA affected survival $(P=0.041)$ when chicks were exposed to $50(P=0.089), 100(P=0.089)$, and $200(P=0.005)$ ants (Table 1$)$.

\section{Body Mass}

We found a correlation between mean number of RIFA on chicks (Table 1) and number of RIFA in beakers for both 15 second $(r=0.992$, $P=0.078)$ and 60 second $(r=0.995, P<0.001)$ treatments. Body mass was affected by number of RIFA ( $P=0.001)$, and showed effects at 1 $(P=0.001), 3(P=0.001), 5(P=0.004), 7(P$ $=0.003)$, and $9(P=0.007)$ days after treatment. However, only chicks exposed to 200 RIFA for 60 seconds showed lower body mass than controls on each sampling day $(P<0.1$; Fig. 1). Duration of exposure (15 vs. $60 \mathrm{sec})$ also negatively influenced chick body mass $(P=0.067)$, but only when chicks were exposed to 200 RIFA $(P=0.003$; Fig. 1).

\section{DISCUSSION}

Exposure to as few as 50 RIFA for 60 seconds and 200 RIFA for 15 seconds negatively affected survival of quail chicks. These exposures corresponded to as few as 6.5 and 22.5 ants on a chick. We observed RIFA repeatedly stinging, once they had climbed onto a chick. We assumed that quail chicks died $(n=16)$ from repeated stings by RIFA. However, exact causes of death (e.g., toxicosis, general stress response) 
were not determined. When stinging, RIFA bite the victim with their mandibles and inject 0.01 to $0.11 \mathrm{uL}$ of venom; repeated stinging is common (Fox et al. 1982). RIFA venom is $99 \%$ piperidine alkaloids with hemolytic, insecticidal, cytotoxic (Fox et al. 1982), fungicidal (Blum and Callahan 1960), and necrotic properties (Brown 1972). Fire ant stings have been documented to affect survival of pipping chicks (Johnson 1961, Dewberry 1962), but not older quail chicks. Mortality during various life stages has been reported in other avian species (Wilson and Silvy 1988). Continuous exposure in the wild to $\geq 50$ RIFA for 60 seconds or $\geq 200$ RIFA for $\geq 15$ seconds seems unlikely. However, quantitative field data are lacking, and given the mass recruitment reaction of disturbed RIFA colonies or foraging columns, stings by large numbers of RIFA may be possible.

Body mass of northern bobwhite chicks was negatively affected by RIFA only when exposed to 200 ants for 60 seconds. The exact causes of these negative effects on body mass (e.g., stress response) were not determined. However, by decreasing chick body mass gain, RIFA could affect quail recruitment because chick size may be related to survival (Parsons 1970, Galbraith 1988, Grant 1991).

\section{MANAGEMENT IMPLICATIONS}

The red imported fire ant, a native of the Pantanal region of South America, has been established in the United States for slightly more than 50 years. In the United States, RIFA apparently have experienced ecological release, and have rapidly spread throughout the Southeast where temperature, moisture, and habitat variables are favorable. Eventually, RIFA are expected to invade successfully one-fourth of the United States (Vinson and Sorensen 1986). Exposure to RIFA can lead to reduced body mass and survival in northern bobwhite chicks, providing support for Allen et al. (1995) hypothesis that direct exposure to RIFA stings may limit quail populations. If exposure of wild northern bobwhite chicks reaches levels where reduced growth and survival reduces population densities, managers may consider RIFA control. However, the cost of RIFA control may make it impractical in some situations (Allen 1994). Future research should attempt to determine probable exposure rates of wild northern bobwhite chicks to RIFA and recommend cost-effective means of RIFA control.

\section{LITERATURE CITED}

AlLen, C. R. 1994. Responses of wildlife to red imported fire ant population reductions in the South Texas coastal prairie. M.S. Thesis, Texas Tech Univ., Lubbock. 153 pp.

$\longrightarrow$, S. Demarais, AND R. S. Lutz. 1994. Red imported fire ant impact on wildlife: an overview. Texas J. Sci. 46:51-59.

, R. S. LuTz, AND S. Demarais. 1993. What about fire ants and northern bobwhites. Wildl. Soc. Bull. 21:349-351.

$\longrightarrow, \longrightarrow$ AND $\longrightarrow$ 1995. Red imported fire ant impacts on northern bobwhite populations. Ecol. Appl. 5:632-638.

Blum, M. S., AND P. S. Callahan. 1960. Chemical and biological properties of the venom of the imported fire ant (Solenopsis saevissima var. richtert Forel) and the isolation of the insecticidal component. Trans. 1lth Int. Congr. Entomol. (Symp. 3/4):290-293.

Brennan, L. A. 1993. Fire ants and northern bobwhites: a real problem or a red herring. Wildl. Soc. Bull, 21:351-355.

Brown, L. L. 1972. Fire ant allergy. Southern Medical J. 65:273-277.

DEWBERRY, O. 1962. Fire ant control investigations. Fed. Aid in Fish and Wildl. Restor. Proj. W-37-R-1-2. Social Circle, Ga. 44pp.

Fillman, D. A., AND W. L. Sterling, 1983, Killing power of the red imported fire ant (Hym.: Formicidae): a key predator of the boll weavil (Col.: Curculionidae). Entomophaga 28:339-344.

Fox, R. W., R. F. LOCKEY, AND S. C. BUKANTZ. 1982. Neurologic sequelae following the imported fire ant sting. J. Allergy Clinical Immunol. 70:120-124.

Galbrarth, H. 1988. Effects of egg size and composition on the size, quality and survival of lapwing Vanellus vanellus chicks. J. Zool. (Lond.) 214:383-398.

Grant, M. C. 1991. Relationships between egg size, chick size at hatching, and chick survival in the whimbrel, Numenius phaeopus. Ibis 133:127133.

Hunt, A. N., AND H. R. HeRmanN. 1973. Insect envenomization: some hematological reactions in guinea pigs to three hymenopterous venoms. J. Georgia Entomol. Soc. 8:249-264.

JoHnSON, A. S. 1961. Antagonistic relationships between ants and wildlife with special reference to imported fire ants and bobwhite quail in the Southeast. Proc. Ann. Conf. Southeast. Ass. Game and Fish Comm. 15:88-107.

Parsons, J. 1970. Relationship between egg size and post-hatching chick mortality in the herring gull (Larus argentatus). Nature 228:1221-1222.

PORTER, S. D., AND D. A. SAvignano, 1990. Invasion of polygyne fire ants decimates native ants and disrupts arthropod community. Ecology 71: 2095-2106.

SYSTAT. 1992. SYSTAT for Windows: statistics. Version 5. SYSTAT, Inc., Evanston, Ill. 750 pp.

VINSON, S. B., AND A. A. SORENSEN. 1986. Imported fire ants: life history and impact. Tex. Dep. Agric., Austin. 28 pp. 
WhITE, G. C. 1983. Numerical estimation of survival rates from band recovery and biotelemetry data. J. Wildl. Manage: 47:716-728.

WILsON, D. E., AND N. J. SILVY. 1988. Impact of the imported fire ants on birds. Pages 70-74 in Proc. of the Governor's Conf. The red imported fire ant: assessment and recommendations. Sportsmen Conservationists of Texas, Austin.

Received 20 March 1995.

Accepted 23 October 1995

Associate Editor: Fairbrother. 